\title{
Enraizamento e aclimatização de brotos regenerados in vitro de bromélia imperial ${ }^{1}$
}

\author{
VANESSA COELHO NAVES ${ }^{2}$, PATRÍCIA DUARTE DE OLIVEIRA PAIVA ${ }^{3}$, RENATO PAIVA $^{4}$, MOACIR PASQUAL $^{3}$, \\ LEONARDO FERREIRA DUTRA ${ }^{3}$ e LUCIANO VILELA PAIVA ${ }^{5}$
}

\begin{abstract}
RESUMO
Uma das fases relevantes do processo de propagação de plantas in vitro é a indução de enraizamento e a aclimatização. A ineficiência desses processos ou falta de protocolos adequados pode inviabilizar todo o processo de micropropagação. Para a propagação in vitro de bromélias, alguns métodos já estão definidos, mas para a bromélia imperial (Alcantarea imperialis), uma Bromeliaceae nativa brasileira ameaçada de extinção, ainda não há um protocolo definido. Objetivou-se avaliar, neste trabalho, o efeito do regulador de crescimento ANA (ácido naftaleno acético), adicionado em diferentes concentrações $(0,0$; 0,$\left.1 ; 0,5 ; 1,0 ; 2,0 \mathrm{mg} \mathrm{L}^{-1}\right)$ ao meio de cultura MS, sobre a indução de enraizamento em brotos dessa bromélia já regenerados in vitro. Avaliou-se, ainda, o pegamento de mudas aclimatizadas com e sem raízes. O processo de enraizamento é induzido em todas as brotações quando se adiciona ANA ao meio de cultura. Sugere-se utilizar 0,1 $m g \mathrm{~L}^{-1}$ de ANA, pois tal concentração proporciona menor número de brotações secundárias nos brotos a serem aclimatizados, além de ser mais econômica. A aclimatização ocorre com mais eficiência em mudas enraizadas ao final do processo in vitro.
\end{abstract}

Palavras-chave: Bromélia, Alcantarea imperialis.

\section{ABSTRACT \\ Rooting and acclimatization of in vitro regenerated shoots of imperial bromeliad}

Rooting induction and acclimatization are the most important phases during in vitro plant propagation and may affect the process because of its inefficiency and lack of appropriate protocols. Although some methodologies have already been described for in vitro propagation of bromeliads, no protocol has yet been defined for the imperial bromeliad (Alcantarea imperialis), an endangered native Brazilian bromeliaceae. The objective of this work was to evaluate the effect of MS medium supplemented with different NAA concentrations $(0.0 ; 0.1 ; 0.5 ; 1.0$ and $2.0 \mathrm{mg} \mathrm{L}^{-1}$ ) on rooting induction of shoots obtained through in vitro regeneration. The acclimatization of rooted and non-rooted plantlets was also evaluated. Although root induction was observed in all shoots in the presence of NAA, the use of $0.1 \mathrm{mg} \mathrm{L}^{-1}$ is suggested to reduce costs and the number of secondary roots formed. Higher acclimatization efficiency is obtained using rooted plantlets.

Key words: Bromeliad, Alcantarea imperialis.

\footnotetext{
${ }^{1}$ Parte da dissertação de mestrado da primeira autora

${ }^{2}$ Mestre em Fitotecnia, Universidade Federal de Lavras (MG).

${ }^{3}$ Departamento de Agricultura, Universidade Federal de Lavras (UFLA), 37200-000 Lavras (MG). E-mail: pdolivei@ufla.br

${ }^{4}$ Departamento de Biologia, UFLA.

${ }^{5}$ Departamento de Química, UFLA.
} 


\section{INTRODUÇÃO}

As bromélias são plantas de ocorrência exclusiva das Américas. Atualmente, existem classificados 50 gêneros de Bromeliaceae, que apresentam mais de 3.000 espécies, sendo que aproximadamente a metade é encontrada, exclusivamente, no Brasil. Ocupam ambientes desde o nível do mar até altitudes superiores a 4.000 metros; em termos climáticos sobrevivem tanto nas zonas desérticas como nas mais úmidas e resistem a temperaturas próximas de $0{ }^{\circ} \mathrm{C}$ (LEME \& MARIGO, 1993).

As bromélias são consideradas essenciais para a garantia da diversidade dos locais onde ocorrem. Sua roseta tipo tanque, ocorrente em algumas espécies, forma um micro-habitat para diversos grupos de organismos, o que lhes confere um importante papel ecológico (OLIVEIRA et al., 1994).

Pertencendo à subfamília Tillandsioideae, a Alcantarea imperialis (Carrière) Harms (= Vriesea imperialis V. L. Harms) é considerada a imperatriz das montanhas do Estado do Rio de Janeiro, onde ocorre, principalmente, nas escarpas rochosas íngremes em grandes grupamentos populacionais (SMITH \& DOWNS, 1977). A Serra dos Órgãos (Teresópolis - RJ) é uma das principais áreas de extrativismo de bromélias, caso específico da Alcantarea imperialis, pois corresponde à área de distribuição natural da espécie, sendo, portanto, considerada área de risco de extinção (NUNES \& FORZZA, 1998; WANDERLEY, 2001).

A importância econômica das bromélias tem crescido muito nos últimos anos, com sua utilização em projetos paisagísticos devido a sua grande beleza, resistência e praticidade no manuseio. As bromélias são utilizadas tanto na decoração de jardins como em interiores e, hoje, já podem ser encontradas à venda na maioria das floriculturas. A exportação é uma atividade bastante expressiva para colecionadores e comerciantes distribuídos por todo mundo, o que incentiva a coleta ilegal de espécies de maior beleza, acarretando a redução de populações naturais e o aumento do número de espécies em risco de extinção (MELO, 1996).

A exemplo de outros países, já existem no Brasil empresas que se dedicam exclusivamente à produção massal de mudas de bromélias para fins ornamentais, utilizando técnicas de cultura de tecidos, e visando abastecer mercados internos e externos (ZORNING, 1996).

Segundo WANDERLEY (2001), a produção em estufas de Alcantarea imperialis ainda é muito pequena e muitos dos exemplares comercializados são retirados de seu ambiente natural e vendidos ilegalmente, por isso a recomendação de adquirir bromélias somente de produtores e vendedores credenciados pelo Instituto Brasileiro do Meio Ambiente (IBAMA).

A cultura de tecidos é a principal forma de obtenção de plântulas de bromélias em escala comercial. A semeadura é utilizada apenas para selecionar matrizes a partir de híbridos ou de espécies naturais nativas ou exóticas (NUNES \& FORZZA, 1998). Para o setor de floricultura, as técnicas de cultura de tecidos vêm sendo amplamente utilizadas para a propagação clonal de um grande número de espécies, pois a multiplicação é rápida e a qualidade, uniformidade e quantidade de plantas produzidas são maiores em relação às obtidas por métodos convencionais (GATTI, 1992). Segundo MERCIER \& KERBAUY (1994), a taxa de multiplicação de bromélias in vitro é geralmente muito superior àquela conseguida in vivo.

A aclimatização é apontada como uma das fases mais críticas do processo de micropropagação de plantas. Porém, de maneira geral, os trabalhos de micropropagação não relatam os procedimentos, dificuldades e soluções para o processo de aclimatização (CARNEIRO, 1997).

COZAI \& KITAYA (1995) analisaram os componentes do ambiente in vitro e listaram as seguintes características relativas à parte aérea de plantas obtidas por micropropagação: redução na taxa fotossintética líquida em conseqüência do baixo fluxo fotônico, diminuição da transpiração, redução no fluxo de radiação térmica líquida e elevada taxa respiratória. Quanto à parte radicular, ocorre redução na absorção de água, íons e açúcar. Além disso, as condições de umidade relativa, a temperatura do ar, a concentração de $\mathrm{CO}_{2}$, a alta concentração de íons, açúcar e reguladores de crescimento in vitro tendem a ser alterados quando a planta é transferida para o local onde será submetida às condições de aclimatização, dificultando seu desenvolvimento. A presença de raízes nas plântulas, também, pode influenciar. Algumas espécies adaptam-se muito bem ao processo de aclimatização sem a formação prévia de raízes, enquanto que outras necessitam das raízes para se adaptarem.

Outra condição importante para o sucesso da formação de mudas na fase de aclimatização ex vitro é o tipo de substrato utilizado, por causa dos efeitos proporcionados na translocação de água no sistema solo-planta-atmosfera e da facilidade para o estabelecimento da arquitetura do sistema radicular (SPURR \& BARNES, 1973). A escolha do material a ser utilizado como subs- 
trato depende não só do objetivo a ser alcançado, mas, também, da disponibilidade no local, custo de aquisição e experiência do viveirista (KÄMPF, 1992).

Plantas epífitas, como as bromélias, exigem substratos de baixa densidade, alta permeabilidade e aeração. A presença de elevada fração de matéria orgânica no meio de cultivo pode melhorar tais características. Misturas com solo mineral podem ser usadas para o cultivo em recipientes, desde que sejam adicionados condicionadores para diminuir o peso e/ou aumentar a porosidade do meio (KÄMPF, 1992).

As bromélias são plantas que se adaptam melhor em substratos ácidos ( $\mathrm{pH} 4,5$ a 5,5), podendo ser utilizados turfa, casca de pinus e poliuretano na composição do substrato de cultivo (JIMENEZ \& CABALLERO, 1990). CARNEIRO (1997) utilizou, com sucesso, o Plantmax ${ }^{\circledR}$ na aclimatização de bromélias.

O presente trabalho objetivou testar o efeito da auxina ANA no enraizamento in vitro de brotações da bromélia Alcantarea imperialis e a aclimatização das plântulas obtidas.

\section{MATERIAL E MÉTODOS}

Visando identificar concentrações adequadas de ANA (ácido naftaleno acético) para indução de enraizamento in vitro, adicionou-se esse regulador nas concentrações: 0,$1 ; 0,5 ; 1,0$ e 2,0 $\mathrm{mg} \mathrm{L}^{-1}$, além da testemunha, ao meio de cultura MS (MURASHIGE \& SKOOG, 1962). Foram acrescentados, ainda, $7 \mathrm{~g} \mathrm{~L}^{-1} \mathrm{de}$ ágar, sendo o $\mathrm{pH}$ ajustado para 5,8 antes do processo de autoclavagem, realizado a $121^{\circ} \mathrm{C}$ e $1 \mathrm{~atm}$, por 20 minutos.

Os explantes utilizados foram brotações obtidas no processo de multiplicação in vitro, após 120 dias de cultivo. As brotações inoculadas foram padronizadas, apresentando altura entre 1 e $2 \mathrm{~cm}$. O experimento foi conduzido em sala de crescimento com fotoperíodo de 16 horas, intensidade luminosa de 3000 lux e temperatura de $26 \pm 1^{\circ} \mathrm{C}$.

O delineamento estatístico utilizado foi o inteiramente casualizado com quatro repetições. Cada unidade experimental foi constituída por quatro tubos de ensaio contendo uma planta cada um. A avaliação foi realizada aos 60 dias, observando-se a ocorrência de raízes, tamanho de raiz, altura da parte aérea e número de brotos.

Para aclimatização, foram utilizadas brotações com e sem raízes, com o objetivo de avaliar a adaptação ex vitro. Os brotos foram plantados em bandejas de isopor de 120 células, contendo Plantmax ${ }^{\circledR}$ como substrato, e mantidos sob Sombrite ${ }^{\circledR} 80 \%$ em casa-devegetação, com irrigação intermitente, em temperatura média de $25^{\circ} \mathrm{C}$. Foram utilizadas 30 plantas com raiz e 30 sem raiz, em três repetições. As plantas foram avaliadas após 30 dias, observando-se a porcentagem de sobrevivência das mudas, e aplicando teste de média sobre os resultados.

\section{RESULTADOS E DISCUSSÃO}

Todos os parâmetros avaliados apresentaram respostas significativas em função das diferentes concentrações de ANA. Quando os brotos não foram tratados com ANA acrescido ao meio de cultura, o percentual de enraizamento foi de $56,25 \%$, entretanto, quando se adicionou esse fitorregulador ao meio de cultura, nas concentrações de 0,1 a $2,0 \mathrm{mg} \mathrm{L}^{-1}$, observou-se $100 \%$ de brotos enraizados. Assim, podese indicar a utilização de $0,1 \mathrm{mg} \mathrm{L}^{-1}$ de ANA acrescido ao meio de cultura, para indução do enraizamento in vitro em brotos de bromélias.

De acordo com TOMBOLATO et al. (1991), o ANA é a auxina mais utilizada na multiplicação, em concentrações inferiores a $0,5 \mathrm{mg} \mathrm{\textrm {L } ^ { - 1 }}$. Embora GRATTAPAGLIA \& MACHADO (1998) afirmem que concentrações elevadas de auxinas podem inibir a multiplicação e favorecer a formação de calos, no presente trabalho esse efeito não foi verificado até a concentração de $2 \mathrm{mg} \mathrm{L}^{-1}$.

Contrariando os resultados obtidos, CARNEIRO (1997) obteve enraizamento in vitro em Cryptanthus sinuosus, Neoregelia cruenta e Quesnelia arvensis sem a utilização de auxinas no meio de cultura, salientando o fato de que as diferentes espécies possuem potenciais de enraizamento distintos.

O maior tamanho das raízes formadas $(3,9 \mathrm{~cm})$ foi obtido na concentração de $1,58 \mathrm{mg} \mathrm{L}^{-1}$ de ANA (Figura 1A). As auxinas induzem a iniciação radicular, entretanto, inibem a elongação das raízes (TAIZ \& ZEIGER, 2004). Geralmente, a utilização desses fitorreguladores objetiva não só aumentar o percentual de enraizamento, mas, também, acelerar a iniciação, o número e qualidade de raízes (FACHINELLO et al., 1994).

Os menores tamanhos de raízes obtidos a partir da concentração de $1,58 \mathrm{mg} \mathrm{L}^{-1}$ de ANA, provavelmente, sejam devidos ao efeito fitotóxico desse fitorregulador. De acordo com FACHINELLO et al. (1994), o aumento da concentração de auxina exógena aplicada provoca efeito estimulador de raízes até um valor 
máximo, a partir do qual qualquer acréscimo tem efeito inibitório.

A altura de plântulas apresentou comportamento semelhante, obtendo o maior valor $(7,9 \mathrm{~cm})$ na concentração de $1,56 \mathrm{mg} \mathrm{L}^{-1}$ de ANA (Figura 1B). Em função dessa resposta, pode-se inferir que o crescimento da parte aérea é diretamente proporcional ao tamanho das raízes. FRÁGUAS et al. (2002), em trabalho com a espécie Aechmea bromelifolia, testaram concentrações do meio MS e sacarose e obtiveram plântulas com 5,79 $\mathrm{cm}$ de altura.

O maior número de brotos $(1,7)$ foi obtido com a concentração de $1,30 \mathrm{mg} \mathrm{L}^{-1}$ de ANA (Figura 1C).
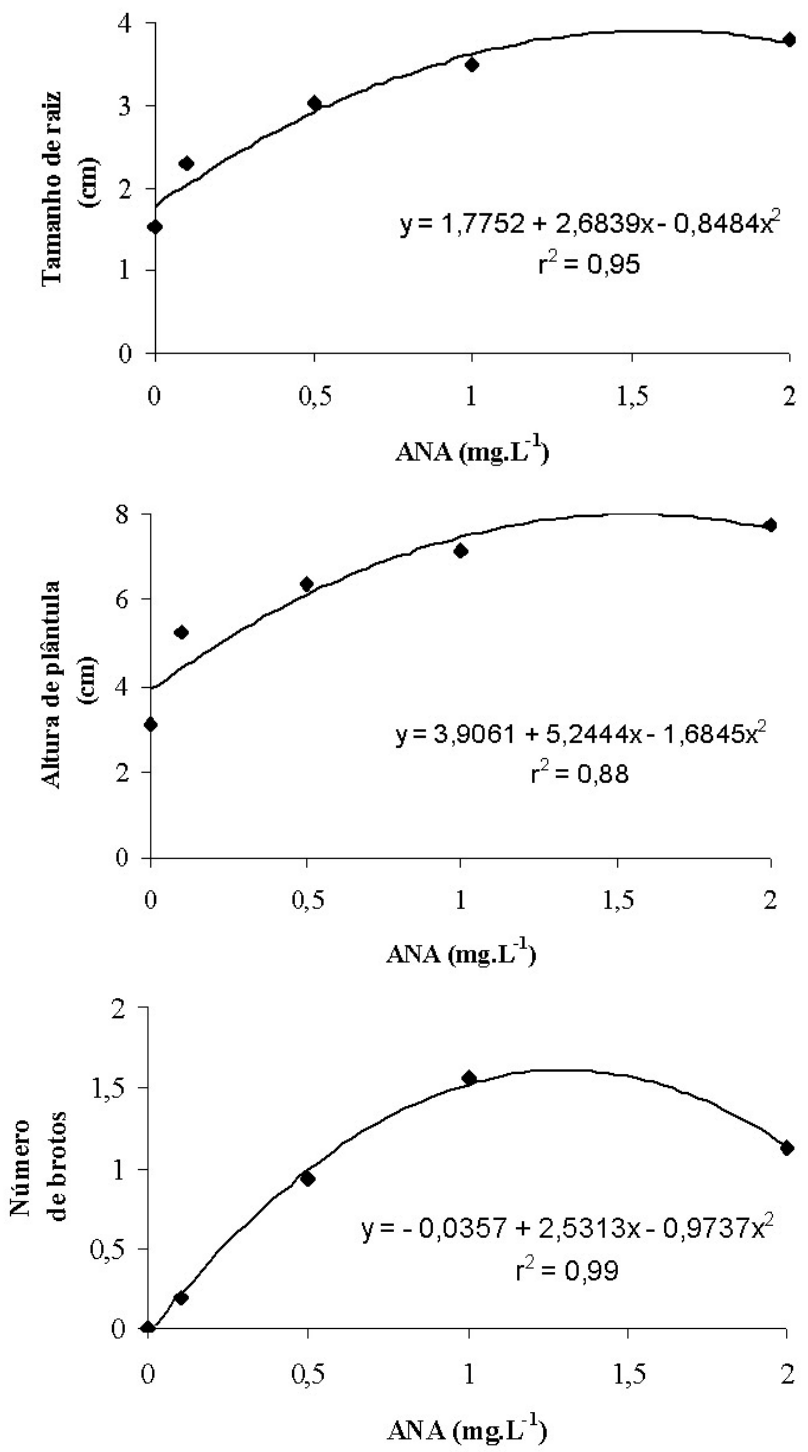

Figura 1. Efeito de diferentes concentrações de ANA sobre o enraizamento dos brotos (A), tamanho de plântula (B) e número de brotos (C) de Alcantarea imperialis
Embora tenham sido emitidas menos de duas brotações por explante, esse resultado pode ser útil se o objetivo for a multiplicação in vitro, quando se busca aumentar o número de plântulas produzidas. JONES \& MURASHIGE (1974), em trabalho com as espécies Aechmea fasciata, Cryptanthus bivitathus, Dyckia sulphurea, Cryptbergia meadii e Guzmania sp,. e DAVIDSON \& DONNAN (1977), com Cryptanthus bivitathus, também obtiveram formação de brotos nessas espécies utilizando como explantes gemas axilares.

Em contrapartida, a emissão de novos brotos é indesejável na fase de enraizamento, pois prejudica a conformação da planta, diminuindo a qualidade comercial da muda destinada à aclimatização.

As plântulas demonstraram grande capacidade de adaptação ao ambiente ex vitro. Os brotos enraizados submetidos à aclimatização obtiveram $98 \%$ de sobrevivência, enquanto que apenas $72 \%$ dos brotos não enraizados sobreviveram, apresentando raízes incipientes. As diferenças entre as porcentagens de sobrevivência foram estatisticamente significativas. De acordo com esse resultado, constata-se a necessidade de se realizar o enraizamento in vitro antes da aclimatização. Esse processo, apesar de aumentar o tempo de propagação em laboratório em 60 dias, proporciona melhor pegamento das mudas. CARNEIRO (1997), trabalhando com as espécies Neoregelia cruenta, Cryptanthus sinuosus e Alcantarea imperialis, obteve sucesso na aclimatização em substrato Plantmax ${ }^{\circledR}$. De acordo com MERCIER \& KERBAUY (1994), bromélias obtidas in vitro, em geral, não apresentam dificuldade para aclimatização.

\section{CONCLUSÕES}

Conforme os resultados obtidos, a utilização de ANA a $0,1 \mathrm{mg} \mathrm{L}^{-1}$ na micropropagação da bromélia Alcantarea imperialis pode ser recomendada, visto que essa concentração induziu o enraizamento em $100 \%$ dos brotos, com pequena formação de brotações secundárias.

\section{REFERÊNCIAS BIBLIOGRÁFICAS}

CARNEIRO, L.A. Controle da morfogênese in vitro de três espécies de bromélias endêmicas do Sudeste brasileiro. Piracicaba: ESALQ, 1997. 87p. (Tese - Doutorado em Agronomia). 
COZAI, T. \& KITAYA, Y. Enviromental control for large scale production of in vitro plantles. In: TERZI, M.; CELLA, R.; FALAVIGNA, A. (Eds.). Current Issues in Plant Moleculars Biology, London: Kluwer Academic Publishers, 1995, p.659-667.

DAVIDSON, S.E. \& DONNAN, A. In vitro propagation of Cryptanthus spp. Proceeding of the Florida State Horticultural Society, Orlando, v.90, p. 303-304, 1977.

FACHINELLO, J.C.; HOFFMANN, A.; NACHTIGAL, J.C.; KERSTEN, E. \& FORTES, G.R. de L. Propagação de plantas frutíferas de clima temperado. Pelotas: UFPel, 1994. 179p.

FRÁGUAS, C.B.; PASQUAL, M.; DUTRA, L.F. \& CHAGAS, E.A. Desenvolvimento in vitro de plântulas de bromélia: sacarose e concentrações do meio MS. Revista Científica Rural, v.7, n.2, p.55-63, 2002.

GATTI, A.C. Cultura de Tecidos em Plantas Ornamentais. In: UNIVERSIDADE DE MARINGÁ. Manual de Floricultura, Maringá, 1992, p.28-35.

GRATTAPAGLIA, D.; MACHADO, M.A. Micropropagação. In: TORRES, A.C.; CALDAS, L.S. \& BUSO, J.A. Cultura de Tecidos e Transformação Genética de Plantas. Brasília: EMBRAPA-SP/EMBRAPA-CNPH, 1998. p.183-260.

JIMENEZ, R.M. \& CABALLERO, M.R. El cultivo industrial de plantas en maceta. Reus: Ediciones de Horticultura, 1990. 664p.

JONES, J.B. \& MURASHIGE,T. Tissue culture propagation of Aechmea fasciata and others bromeliads. Proceeding of the Internacional Plant Propagators Society, Copenhagen, v.24, p.117-123, 1974.

KÄMPF, A.N. Substratos para floricultura. In: UNIVERSIDADE DE MARINGÁ. Manual de floricultura. Maringá, 1992. p.36-43.

LEME, E.M.C. \& MARIGO, L.C. Bromélias na Natureza, Rio de Janeiro, Marigo comunicação visual. 1993. $183 \mathrm{p}$.
MELO, T.B. Bromélias no paisagismo. Revista da Sociedade Brasileira de Bromélias, Rio de Janeiro, v.3, n.1, p.3-7, 1996.

MERCIER, H. \& KERBAUY, G.B. In vitro culture of Vriesea hieroglyphica, an endangered bromeliad from the Brazilian Atlantic Forest. Journal of the Bromeliad Society, Los Angeles, v.44, p.120-124, 1994.

MURASHIGE, T. \& SKOOG, F.A. A revised medium for rapid growth and biossays with tabacco tissue culture. Physiologia Plantarum, Copenhagen, v.15, p.473-497, 1962.

OLIVEIRA. M.G.N.; ROCHA, C.F.D. \& BANGNALL, T. A comunidade animal associada à bromélia-tanque $\mathrm{Ne}$ oregelia cruenta (R. Graham) L.B. Smith. Revista da Sociedade Brasileira de Bromélias, Rio de Janeiro, v.1, n.1, p.22-29, 1994.

NUNES, J.V.C. \& FORZZA, R.C. Bromélias. Projeto: Inventário dos recursos naturais da Mata Atlântica, São Paulo, v.1, n.1, 1998. Disponível em: < http: //www.unicamp.br/ nipe/rbma/bromain.htm>. Acesso em: 04 set. 2001.

SMITH, L.B. \& DOWNS, R.J. Flora neotropica: Bromeliaceae, New York: New York Botanical Gardens, v.14, n.2, p.1268, 1977.

SPURR, S.H. \& BARNES, B.Y. Forest Ecology. New York: The Ronald Press, 1973, 571p.

TAIZ, L. \& ZEIGER, E. Fisiologia Vegetal. Tradução de Eliane Romanato Santarém. 3 ed. Porto Alegre: Artmed, 2004, 719p. Título original: Plant Physiology.

TOMBOLATO, A.F.C.; TAKEBAYASHI, S.S.G.; COSTA, A.M.M. \& QUIRINO, E.A. Cultura in vitro da bromélia. O Agronômico, Campinas, v.43, n.2/3, p.77-78, 1991.

WANDERLEY, M.G L. Beleza tropical. Entrevistador: Luciane Crippa. Natureza, São Paulo, v.156, n.12, p.14-21, jan. 2001. Entrevista.

ZORNING, R.K. Micropropagação de bromélias. Revista da Sociedade Brasileira de Bromélias, Rio de Janeiro, v.3, n.3, p.3-8, 1996. 